\title{
Representações dos cuidadores por crianças institucionalizadas: um modelo grounded
}

\section{Representations of caregivers by institutionalized children: a Grounded model}

\author{
Vânia Gonçalves*, Rui Paixão*, Ana Paula Couceiro* \\ *Universidade de Coimbra
}

\begin{abstract}
Resumo
Neste estudo analisam-se as representações que as crianças institucionalizadas constroem sobre os cuidadores secundários. A informação foi recolhida através de entrevistas a oito crianças e os dados analisados de acordo com a Grounded Theory. Os resultados evidenciam seis categorias incluídas na categorial principal (Vinculação suportativa): "Competência emocional", "Dimensão relacional", "Aspetos da personalidade", "Mundo interno", "Desenvolvimento da autonomia e da diferenciação" e "Regulação emocional". Estes resultados mostram que as crianças percecionam os cuidadores institucionais como disponíveis, reconhecendo a sua capacidade contentora e afetiva. Estabelecem com eles uma relação que parece funcionar como amortecedor das dificuldades vividas nas famílias de origem.

Palavras-chave: crianças institucionalizadas, cuidadores institucionais, centro de acolhimento, representações, grounded theory
\end{abstract}

\begin{abstract}
The present study analyses the mental representations of institutionalized children about their institutional caregivers. The information was collected by the interviews of eight children and data analyzed according to Grounded. The analysis showed six categories (included in the main category "Supportive attachment"): "Emotional competence", "Relational dimension", "Aspects of the personality", "Internal world", "Development of autonomy and differentiation" and "Emotional regulation". Results show that children perceive the institutional caregivers as available figures with supportive, protective and affective capacities. This attachment relationship seems operate as a buffer against the difficulties lived by children's in their families.

Key Words: institutionalized children, institutional caregivers, welfare, representations, grounded theory.
\end{abstract}

O termo vinculação é definido como a propensão dos seres humanos para estabelecerem laços afetivos fortes com determinadas pessoas, ficando o sujeito emocionalmente afetado quando ocorrem separações ou perdas (Bowlby, 1969).

O estabelecimento de uma relação de vinculação é essencial para que uma criança se sinta segura e protegida. A vinculação constitui-se, então, como a base para uma estabilidade emocional futura (Montagner, 1993).

Tendo passado por uma situação de separação, de abandono e/ou morte, as crianças institucionalizadas estão marcadas pela perda e pelo sofrimento (Tinoco \& Franco, 2011). Estas crianças constroem relações de vinculação através da vivência com outras figuras significativas que fomentam o seu desenvolvimento adaptativo, fornecendo-lhes respostas pessoais, afetivas e sociais de qualidade. Estas figuras podem surgir da relação com os professores, com os funcionários da escola, com os pares e, particularmente, com os funcionários da instituição onde vivem (Mota \& Matos, 2010), os quais devem desempenhar uma função suportativa e contentora das vivências prévias destas crianças, incluindo os acontecimentos potencialmente traumáticos com a família de origem e a própria vivência de separação.

Os cuidadores destas crianças devem ter a capacidade de lhes proporcionar estabilidade e confiança, estabelecendo ligações afetivas seguras. A segurança interna que estes transmitem tem uma função protetora que permite o desenvolvimento da capacidade de enfrentar adaptativamente as adversidades (Matos, 2003).

Considerando o papel crucial que o estabelecimento de relações de vinculação tem na vida do ser humano e tendo em conta as vivências das crianças que se encontram num meio institucional, torna-se evidente a importância de investigar e compreender as representações que as crianças constroem acerca dos cuidadores institucionais e de que modo estas se traduzem num elemento de suporte e elaboração das vivências de separação dos cuidadores de quem foram retiradas.

\section{Método}

Procurou-se, através da Grounded Theory, construir uma teoria compreensiva sobre o tipo e função das representações que as crianças institucionalizadas constroem dos seus cuidadores institucionais. 


\section{Participantes}

Foram entrevistadas onze crianças de um Centro de Acolhimento Temporário (CAT), com idades compreendidas entre os 6 e os 12 anos. Contudo, destas onze crianças apenas oito foram estudadas, dado que a saturação teórica dos dados foi obtida à oitava entrevista. $O$ tempo médio de institucionalização das crianças entrevistadas oscila entre o mínimo de um ano e o máximo de dois.

\section{Materiais}

As entrevistas aconteceram num gabinete do CAT selecionado para o efeito. Foram gravadas em registo áudio e realizadas até se atingir a saturação teórica dos dados. Tiveram a duração de vinte e cinco minutos a uma hora e abordaram os seguintes temas: a criança e os cuidadores institucionais; a criança e os outros; recursos internos utilizados em situações de vulnerabilidade; a criança e a sua imaginação.

\section{Procedimento}

As entrevistas foram realizadas depois das devidas autorizações da instituição e de acordo com a disponibilidade das crianças, evitando grandes alterações na dinâmica do CAT.

Durante as entrevistas, a postura das crianças, incluindo a sua espontaneidade, foi considerada um indicador importante da relevância e da sinceridade com que viviam esses aspetos. Assim, a observação do comportamento foi um importante contributo na recolha e posterior análise da informação.

As entrevistas, realizadas individualmente e conduzidas pela primeira investigadora, foram posteriormente transcritas para um documento Word. Embora construídas com base num guião previamente elaborado, realizaram-se num registo informal, promovendo a livre expressão das crianças.

No sentido de assegurar a validade do processo, recorreu-se ao método de triangulação de investigadores, que consiste no envolvimento de múltiplos investigadores no processo de análise dos dados (Denzin, 2009). Este método previne o possível enviesamento de uma análise realizada por uma única pessoa e garante a maior fiabilidade das observações (Denzin, 2009). Assim, todo o processo foi acompanhado, em reuniões semanais, por duas investigadoras que se encontravam a trabalhar com a mesma metodologia.

\section{Resultados}

Tabela 1.

Resultados da análise grounded

\begin{tabular}{|c|c|c|}
\hline $\begin{array}{l}\text { Categoria } \\
\text { Principal } \\
\end{array}$ & Categorias & Subcategorias \\
\hline \multirow{6}{*}{$\begin{array}{l}\text { Vinculação } \\
\text { suportativa }\end{array}$} & $\begin{array}{l}\text { Dimensão } \\
\text { relacional }\end{array}$ & $\begin{array}{l}\text { - Relação positiva com os } \\
\text { cuidadores institucionais; } \\
\text { - Fragilidades na relação } \\
\text { com os cuidadores } \\
\text { institucionais; } \\
\text { - Relação positiva com os } \\
\text { pares; } \\
\text { - Conflito com os pares; } \\
\text { - Relacionamentos } \\
\text { primários percecionados } \\
\text { como positivos; } \\
\text { - Relacionamentos } \\
\text { primários inseguros; } \\
\text {-Competências de } \\
\text { interação; } \\
\text { - Ambiente de holding }\end{array}$ \\
\hline & $\begin{array}{l}\text { Competência } \\
\text { emocional }\end{array}$ & $\begin{array}{l}\text { - Empatia } \\
\text { - Expressão afetiva }\end{array}$ \\
\hline & $\begin{array}{c}\text { Aspetos da } \\
\text { personalidade }\end{array}$ & $\begin{array}{l}\text { Sentimentos de vergonha e } \\
\text { prazer } \\
\text { Autoconceito }\end{array}$ \\
\hline & Mundo interno & $\begin{array}{l}\text { - Medos } \\
\text { - Auto-observação }\end{array}$ \\
\hline & $\begin{array}{c}\text { Desenvolvimento } \\
\text { da autonomia e } \\
\text { diferenciação }\end{array}$ & $\begin{array}{l}\text { - Autonomização } \\
\text { - Diferenciação }\end{array}$ \\
\hline & $\begin{array}{l}\text { Regulação } \\
\text { emocional }\end{array}$ & $\begin{array}{l}\text { - Experiência emocional } \\
\text { positiva e negativa } \\
\text { - Reação positiva e } \\
\text { negativa ao conflito } \\
\text { - Passividade/dinamismo }\end{array}$ \\
\hline
\end{tabular}

\section{Discussão}

$\mathrm{Na}$ presente investigação, verifica-se que os cuidadores institucionais são percecionados como uma base segura disponível para atender às necessidades das crianças, isto é, como disponíveis para a interação, tendo a capacidade de ajudar e proporcionar conforto (Maia, Veríssimo, Ferreira, Silva, \& Antunes, 2011), o que se reflete positivamente ao nível dos comportamentos de autonomia e separação das crianças (Machado, 2007). Inerente ao estabelecimento de uma relação de vinculação com os cuidadores institucionais está a vivência de um ambiente de holding, no qual os cuidadores são percecionados como uma base segura.

Numa relação de vinculação segura, a criança pode expressar-se emocionalmente (Ferreira, 2014), apresentando, também, sentimentos mais elevados de reciprocidade afetiva e de empatia (Cortina, 2013; Oliveira, 2011; Sroufe, 2005), o que se verifica nas afirmações das crianças entrevistadas.

As crianças seguras apresentam, também, uma maior autoestima (Cortina, 2013; Sroufe, 2005). Pode constatar-se a capacidade que as crianças entrevistadas 
têm de reconhecer os seus defeitos, evidenciando-se, assim, de acordo com Clark e Symons (2000), a positividade da relação estabelecida entre as crianças e os seus cuidadores. É, ainda, percetível a preocupação dos cuidadores institucionais relativamente ao estado emocional das crianças. No entanto, parece haver uma certa tentativa de ocultação das fragilidades por parte de algumas crianças, que parece surgir não como evidência da falta de confiança nos cuidadores ou da indisponibilidade destes para abordar questões mais sensíveis, mas sim como uma tentativa das próprias evitarem sentir emoções menos positivas.

Segundo Pinhel, Torres e Maia (2009) quanto maior é a segurança e a coerência das representações de vinculação, menos frequente é a manifestação de comportamentos agressivos. As crianças seguras evidenciam, também, comportamentos de obediência às regras (Cortina, 2013; Sroufe, 2005).

A segurança da vinculação facilita, ainda, a capacidade da criança expressar emoções e regular estados afetivos negativos (Oppenheim \& Waters, 1969).

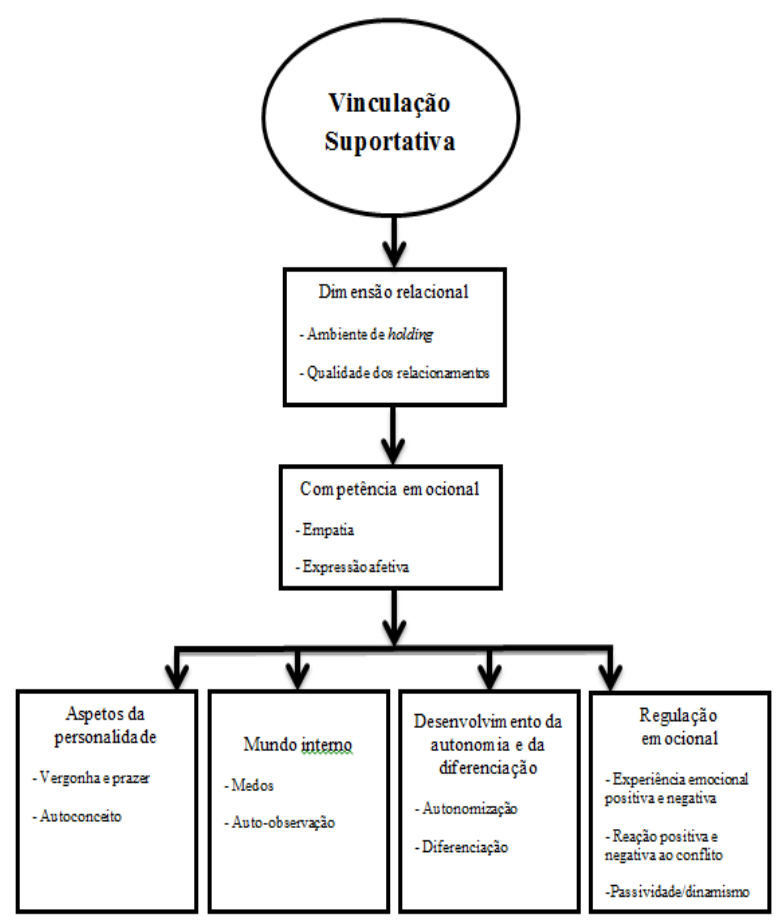

Figura 1. Representações dos cuidadores por crianças institucionalizadas: um modelo grounded

\section{Conclusões}

Dada a importância do estabelecimento de relações de vinculação ao nível do funcionamento psicológico e da regulação dos afetos (Mathews et al., 2016), pretendeu-se com este estudo aceder às representações que as crianças institucionalizadas constroem dos seus cuidadores institucionais e averiguar de que modo a relação estabelecida com estes contribui para a reparação das vivências de separação dos cuidadores de quem foram retiradas.
Verificou-se que, mesmo não lhes tendo sido proporcionadas as condições adequadas ao seu bem-estar e desenvolvimento junto dos cuidadores primários, as crianças entrevistadas mantém o desejo de voltar para eles, evidenciando uma perceção maioritariamente positiva destes seus relacionamentos.

A dor da separação da família de origem pode ser atenuada pelo estabelecimento de uma relação de vinculação com os cuidadores institucionais, adotando estes uma postura contentora que promova a partilha do sofrimento, pensamento e sentimento por parte das crianças (Strecht, 2012).

Efetivamente, constatou-se que as representações que as crianças entrevistadas constroem dos seus cuidadores institucionais são centradas na sua função suportativa, de apoio e no sentimento de confiança e segurança que estes lhes transmitem. A disponibilidade para a partilha de afetos entre crianças e cuidadores institucionais foi, também, denotada.

O estabelecimento de uma relação de vinculação com um cuidador é de extrema importância, pois a ausência de tal relacionamento compromete a vivência de experiências de afeto positivo, a regulação emocional adequada e a aquisição de conhecimentos e expetativas acerca da figura de vinculação como disponível e responsiva, do self como competente, valorizado e capaz de influenciar os outros e do mundo em geral (Bretherton \& Munholland, 1999; Panfile \& Laible, 2012). Realça-se, assim, a importância do estabelecimento de uma relação de vinculação entre as crianças e os cuidadores institucionais, considerando não apenas a sua função reparadora, mas também a influência que acaba por ter em várias dimensões do desenvolvimento das crianças. Constatou-se, ainda, o desenvolvimento de competências empáticas e o incentivo à expressão emocional e ao reconhecimento dos seus defeitos, pois os cuidadores institucionais proporcionam às crianças um ambiente de segurança e confiança. Estes aspetos confirmam a positividade do relacionamento crianças-cuidadores institucionais (Bretherton \& Munholland, 1999; Clark \& Symons, 2000; Sroufe, 2005; Cortina, 2013;).

Conclui-se, assim, que foi possível estabelecer relacionamentos emocionalmente próximos entre crianças e cuidadores institucionais, tendo estes uma função reparadora das suas vivências, o que se refletiu positivamente no desenvolvimento socioemocional das crianças.

\section{Referencias}

Bowlby, J. (1969). Attachment and Loss: Attachment. (2nd ed.). New York: Basic Books.

Bowlby, J. (1993). Attachment and Loss - vol. II, Separation, anxiety and anger (L. Hegenberg, O. Neto, \& M. Hegenberg, Trad.). São Paulo: Martins Fontes. (Obra original publicada em 1973).

Bretherton, I., \& Munholland, K. A. (1999). Internal working models in attachment relationships. In Cassidy, J., \& Shaver, P. R. (eds.), Handbook of Attachment: theory, research, and clinical applications (pp. 89-111). New York: Guildford Press. 
Clark, S. E., \& Symons, D. K. (2000). A Longitudinal Study of Q-Sort Attachment Security and Self-processes at Age 5. Infant and Child Development, 9, 91-104. http://dx.doi.org/10.1002/1522-7219(200006)9:2<91:: AID-ICD218>3.0.CO;2-O

Cortina, M. (2013). The Use of Attachment Theory in the Clinical Dialogue with patients. Psychodynamic Psychiatry, 41, 397-418. http://dx.doi.org/10.1521/pdps.2013.41.3.397

Denzin, N. K. (2009). The Research Act: A Theoretical Introduction to Sociological Methods. Chicago: AldineTransaction.

Ferreira, P. S. O. (2014). A Relação entre a Qualidade da Vinculação e o Desenvolvimento Emocional de Crianças em Idade Pré-escolar (Tese de Mestrado não publicada). Instituto Superior de Psicologia Aplicada, Lisboa. http://hdl.handle.net/10400.12/3319

Machado, T. S. (2007). Padrões de vinculação aos pais em adolescentes e jovens adultos e adaptação à Universidade. Revista Portuguesa de Pedagogia, 41(2), 5-28. http://iduc.uc.pt/index.php/rppedagogia/article/view/1 194

Maia, J., Veríssimo, M., Ferreira, B., Silva, F., \& Antunes, M. (2011). Singularidades de Género nas Representações de Vinculação Durante o Período Pré-escolar. Psicologia: Reflexão e Crítica, 25, 491-498. http://dx.doi.org/10.1590/S0102.79722012000300008

Mathews, S., Onwumere, J., Bissoli, S., Ruggeri, M., Kuipers, E., \& Valmaggia, L. (2016). Measuring attachment and parental bonding in psychosis and its clinical implications. Epidemiology and Psychiatric Sciences, 25 , 142-149. http://dx.doi.org/10.1017/S2045796014000730

Matos, P. M., (2003). O conflito à luz da teoria da vinculação. In M. E. Costa (eds.), Gestão de conflitos na escola (pp. 143-191). Lisboa: Universidade Aberta.

Montagner, H. (1993). A vinculação: a aurora da ternura. Lisboa: Instituto Piaget.

Mota, C. P., \& Matos, P. M. (2010). Adolescentes institucionalizados: $\mathrm{O}$ papel das figuras significativas na predição da assertividade, empatia e autocontrolo. Análise Psicológica, 2, 245-254. http://dx.doi.org/10.14417/ap.278

Oliveira, F. N. V. F. (2011). A qualidade da vinculação em idade escolar: perspectivas cruzadas de mães e filhos (Tese de Mestrado não publicada). Instituto Superior Miguel Torga, Coimbra. http://repositorio.ismt.pt/handle/123456789/144

Oppenheim, D., \& Waters, H. S. (1995). Narrative processes and attachment representations: Issues of development and assessment. Monographs of the Society for Research in Child Development, 60, 197-215. http://dx.doi.org/10.2307/1166179

Panfile, T. M., \& Laible, D. J. (2012). Attachment Security and Child's Empathy: The Mediating Role of Emotion Regulation. Merril-Palmer Quarterly, 58, 1-21. http://dx.doi.org/10.2307/23098060

Pinhel, J., Torres, N., \& Maia, J. (2009). Crianças institucionalizadas e crianças em meio familiar de vida: Representações de vinculação e problemas de comportamento associado. Análise Psicológica, 4(27), 509-521. http://hdl.handle.net/10400.12/255

Sroufe, L. A. (2005). Attachment and development: A prospective, longitudinal study from birth to adulthood. Attachment \& Human Development, 7, 349-367.

http://dx.doi.org/10.1080/14616730500365928

Strauss, A., \& Corbin, J. (1990). Basics of Qualitative Research: Grounded Theory Procedures and Techniques. London: Sage Publications.

Strecht, P. (2012). Crescer vazio: repercussões psíquicas do abandono, negligência e maus tratos em crianças e adolescentes. ( $5^{\mathrm{a}}$ ed.). Lisboa: Assírio e Alvim.

Tinoco, V., \& Franco, M. H. P. (2011). O luto em instituições de abrigamento de crianças. Estudos de Psicologia, 28 427-434. http://dx.doi.org/10.1590/S0103-166X201100040000 3 